
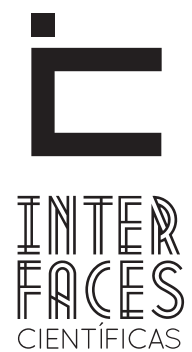

DIREITO

ISSN IMPRESSO 2316-3321

E - ISSN 2316-381X

DOI - 10.17564/2316-381X.2019v7n1p57-68

DOSSIÊ “30 ANOS DA CONSTITUIÇÃO FEDERAL: GANHOS, PERDAS E DESAFIOS EM MATÉRIA DE DIREITOS HUMANOS".

\title{
CONJUGALIDADE, FAMÍLIA E VIOLÊNCIAS DE GÊNERO: ALGUMAS REFLEXÕES A PARTIR DA CONSTITUIÇÃO FEDERAL DE 1988 TRINTA
}

CONJUGALITY, FAMILY AND GENDER VIOLENCE: SOME REFLECTIONS FROM THE 1988 FEDERAL CONSTITUTION YEARS LATER

CONYUGALIDAD, FAMILIA Y VIOLENCIAS DE GÉNERO: ALGUNAS REFLEXIONES A PARTIR DE LA CONSTITUCIÓN FEDERAL DE 1988 TREINTA AÑOS DESPUÉS

Claudia Regina Nichnig ${ }^{1}$

\section{RESUMO}

Este artigo pretende trazer algumas de minhas inquietações de pesquisa, que entrelaçam os estudos de gênero, feministas e a ciência jurídica. Refletindo sobre os ganhos, perdas e desafios em matérias de direitos humanos após 30 anos da Constituição Federal. Minha proposta é trazer algumas provocações a partir de duas importantes temáticas: o direito a uma vida sem violências no ambiente doméstico e familiar e as mudanças no direito de família, como o reconhecimento da conjugalidade de pessoas do mesmo sexo como entidade familiar. Discutirei a importância da existência de legislações, sua efetivação e a necessidade de constante vigilância em relação a implementação e o cumprimento dos direitos conquistados, utilizando as lentes dos estudos de gênero e feministas.

\section{PALAVRAS-CHAVE}

Conjugalidade. Família. Violências de Gênero. Estudos de Gênero e Feministas. 


\section{ABSTRACT}

This article aims to bring some of my research concerns, which intertwined gender studies, feminist and legal science. Reflecting on gains, losses and challenges in human rights matters after 30 years of the Federal Constitution my proposal is to bring some provocations from two important themes: the right to a life without domestic and family violence and the changes in family law, as the recognition of same-sex conjugality as a family entity. I will discuss the im- portance of laws, your effectiveness and the need for constant vigilance regarding its implementation and acquired right compliance, using the lenses of gender and feminist studies.

\section{KEYWORDS}

Conjugality. Family. Gender violence. Gender and Feminist studies.

\section{RESUMEN}

A través de este artículo pretendo exponer algunos de mis intereses de investigación, que entrelazan los estudios de género, estudios feministas y la ciencia jurídica. Reflexionando sobre los avances, pérdidas y desafíos en materia de derechos humanos, después de 30 años de la Constitución Federal, mi propuesta es aportar ciertas provocaciones a partir de dos importantes temáticas: el derecho a una vida sin violencias en el ambiente doméstico y familiar y, por otro lado, los cambios en el derecho de familia, tal como el reconocimiento de la conyugalidad de personas del mismo sexo como entidad familiar. Utilizando una mirada desde los estudios de género y feministas, discutiré la importancia de la existencia de legislaciones, su efectividad y la necesidad de control constante en relación a su implementación y el cumplimiento de los derechos conquistados.

\section{PALABRAS CLAVE}

Conyugalidad. Familia. Violencias de Género. Estudios de Género y Feministas 


\section{CAMPO DOS ESTUDOS DE GÊNEROEFEMINISTAS}

A partir dos estudos das teorias feministas e de gênero que realizei durante minha formação, percebi a necessidade de articular a ciência jurídica com esses estudos e teorias. Não somente o diálogo com o direito, mas as propostas epistemológicas interdisciplinares e dos estudos feministas e de gênero, propõem uma nova perspectiva para os estudos das ciências, ao criticarem a suposta neutralidade, universalidade e objetividade da ciência tradicional. Ao proporem uma nova relação entre o sujeito e objeto a proposta interdisciplinar e feminista propõem que a contextualização e experiência devem estar presentes no processo científico, sendo consideradas na escolha dos temas e na escrita das narrativas. As contribuições de cientistas como Sandra Harding, citada por Renata Reynaldo a qual argumenta

\begin{abstract}
[...] que a voz da ciência é masculina, que a história foi escrita a partir do ponto de vista dos homens de classes e raças dominantes e que as epistemologias tradicionais não só excluem a possibilidade de que as mulheres sejam agentes de conhecimento como também ignoram a relevância da origem dos problemas e hipóteses científicos". (REYNALDO, 2016, p. 33).
\end{abstract}

As explicações propostas por Sandra Harding nos fazem refletir sobre a não neutralidade da ciência, no mesmo sentido que propõe a professora Donna Haraway, para a qual os estudos feministas e de gênero conduzem uma crítica a cientificidade do século XIX, pensando no que seria chamado de "saberes localizados" (HARAWAY, 1995).

As pesquisas desenvolvidas sob uma perspectiva feminista:

Defienden que el sujeto del conocimiento es un individuo histórico particular cuyo cuerpo, intereses, emociones y razón están constituidos por su contexto histórico concreto, y son especialmente relevantes para la epistemología. (GONZÁLES GARCÍA; SEDEÑO, 2002, p.12).

Desta forma, ao produzirem legislações que afetam os direitos das mulheres não podemos deixar de considerar que estas leis refletem sobre as vidas, os corpos, as relações existentes entre mulheres e homens. Assim, como as relações sociais entre homens e mulheres são desiguais, marcadas por opressões e violências, legislações são necessárias para minimizar as desigualdades existentes.

Então não há neutralidade nem nos/nas legisladores, nos operadores do direito e também não existe no que se refere aos/as pesquisadores/as e seus objetos, como propõe o direito. Posso dizer que existem sistemas de moralidades nos julgamentos das pessoas pelos operadores do direito (CORREA, 1981, 1983; RIFIOTIS, 2008, 2010, 2012; BRAGAGNOLO, 2012), e nos casos que iremos tratar muitas vezes quem merece proteção é que julgado/a.

Para pensar na não neutralidade e na desigualdade no acesso as políticas públicas e no julgamento, Anne Marie Goetz (2008) auxilia com o conceito de justiça de gênero que é utilizado por ativistas e acadêmicas para pensar que "igualdade de gênero" ou "integração da perspectiva de gênero no conjunto das políticas", não dão conta quando refletimos em relação as injustiças baseada no gênero que sofrem as mulheres. Portanto, ao incluir a ideia de uma justiça de gênero incluo uma perspectiva política, que considera a subordinação das mulheres aos homens, à família e a desigualdade que recai sobre as mulheres no acesso à justiça de forma desigual (SILVA; WRIGHT, 2016).

O direito é uma das áreas científicas pouca receptivas para o diálogo com outras disciplinas, principalmente em relação as ciências humanas, sendo que as/ os pesquisadora/es se apropriam de debates teóricos, mas raramente fazem pesquisas empíricas em direito, o que vem se modificando lentamente (SILVA, 2018). Ressalto que alguns campos do direito têm fomentado os estudos interdisciplinares, chamando atenção para o diálogo com diferentes áreas das ciências humanas, como é o caso do direito de família.

Nessa área tem se entendido que para a solução de conflitos familiares e evitar processos que se arrastam por muitos anos na Justiça, a utilização do conhecimento teórico da psicologia e do serviço social, por exemplo, ainda de técnicas como a mediação tem sido 
cada vez mais utilizados para a resolução dos mesmos. Entretanto apesar de compreender a importância e a necessidade da mediação e conciliação, entendo que em algumas temáticas como as que envolvem as violências contra as mulheres não são passíveis de mediação, conciliação ou serem intermediadas por conciliadores/as que trabalham com o direito sistemático, como desenvolverei a seguir.

Assim, apresento dois grandes temas que foram considerados grandes avanços dispostos na constituição Federal de 1988 que se relacionam ao direito das mulheres e ao direito de família: a previsão de uma legislação que coíbe expressamente as violências contra as mulheres no âmbito doméstico e familiar e o reconhecimento da união estável como entidade familiar.

Apresentarei uma relação com os princípios constitucionais previstos na Constituição Federal, para em seguida apresentar os avanços e retrocessos em relação as duas temáticas propostas.

\section{OS PRINCÍPIOS CONSTITUCIONAIS}

Primeiramente, para adentrar os temas que me proponho a tratar é preciso dizer que estes foram embasados nos princípios constitucionais, principalmente no princípio da igualdade, da dignidade da pessoa humana, da não discriminação e da liberdade.

A Constituição da República Federativa do Brasil destaca, em seu artigo $1^{\circ}$, que seus fundamentos são os seguintes: a soberania, a cidadania, a dignidade da pessoa humana, os valores sociais do trabalho e da livre iniciativa e o pluralismo político, os quais são princípios fundamentais de direitos humanos, expressos no texto constitucional brasileiro.

A utilização dos princípios constitucionais como instrumento para a garantia dos direitos fundamentais, em que "a interpretação constitucional de princípios, por ser indissociável de uma argumentação prática moral, conduz a uma reconstrução do texto constitucional” (NIGRO, 2012, p. 158).

0 respeito à dignidade da pessoa humana, além de ser um fundamento da República Federativa do Bra- sil, é um dos princípios de nossa Constituição, em seu artigo 3, inciso IV. O princípio da Dignidade da Pessoa Humana é utilizado com frequência quando se trata de questões de família. Segundo Pietro Perlingieri (2002, p. 243):

[...] a família é valor constitucionalmente garantido nos limites de sua conformação e de não contraditoriedade aos valores que caracterizam as relações civis, especialmente a dignidade humana: ainda que diversas possam ser as suas modalidades de organização, ela é finalizada à educação e à promoção daqueles que a ela pertencem.

De acordo com Roger Raupp Rios (2011, p. 90), o princípio da dignidade da pessoa humana "é um direito humano básico". Ligado aos direitos da personalidade, o princípio da dignidade da pessoa humana é fundamental para pensarmos os direitos das mulheres e das populações LGBTTTQI1.

Especificamente nas questões que se relacionam ao direito de família, a igualdade civil é uma reivindicação que se faz presente no contexto brasileiro. Considerada uma das mais importantes bandeiras de reivindicações das feministas, desde os anos 1970, no Brasil, a reivindicação pela igualdade está presente no direito civil francês, que apresenta demandas específicas por leis anti-discriminatórias, pugnando por igualdade em relações às mulheres e aos homossexuais. 0 princípio da igualdade é utilizado para demonstrar que homens e mulheres são iguais perante a lei e também que todos é possível unir-se em família. É trazido para confirmar a igualdade entre heterossexuais e homossexuais, na possibilidade de constituir-se em família.

Assim, a igualdade de gênero, pode ser visto como importante meio de fortalecimento das mulheres para aqueles que defendem a necessidade de políticas afirmativas em seu favor. As políticas públicas para as mulheres que são frutos dos movimentos feministas e de mulheres, têm como objetivo o empoderamento e a conquista de novos direitos, visando entre outras, a participação das mulheres nos espaços de poder, como legislativo, executivo e judiciário. Especial1 Sigla que significa Lésbicas, Gays, Bissexuais, Transexuais, Travestis, Transgêneros, Intersexuais e Queers. 
mente na política, são implantadas ações afirmativas como estabelecimento de cotas para as candidaturas de mulheres no legislativo (JUREMA, 2001).

Fanny Tabak e Florisa Verucci (1994, p. 34) ao analisarem legislações sobre as mulheres, tratam da necessidade da proteção jurídica:

\begin{abstract}
A existência formal de uma lei - mesmo quando sua implementação é deficiente ou quando ainda depende de regulamentação - tem um peso considerável em muitas sociedades. Para a grande maioria da população, a lei tem valor não apenas simbólico, mas ela é encarada como legitimação de atos executados ou a aprovação de determinados comportamentos sociais. A lei legitima as relações sociais, pode ser utilizada para apoiar determinados tipos de relações sociais ou, ao contrário, declará-los inadequados. Portanto, o poder de convicção - ou pressão social - exercido pela lei pode ser muito forte.
\end{abstract}

Ao tratarmos de igualdade também podemos pensar que não há que se falar na "existência de dois pesos e duas medidas, ao mesmo tempo com consequências protetoras e positivas para uns (heterossexuais) e prejudiciais e negativas para outros (homossexuais) é, sem dúvida, uma volição do direito de igualdade" (RIOS, 2011, p. 93). E Rios (2011, p. 93) conclui que esta desigualdade jurídica implica na existência de "um contexto frontalmente oposto àquilo que o princípio da igualdade manda: não discriminar”.

Mesmo que não tenha previsão expressa na Constituição Federal, a não discriminação por "orientação sexual”, a proibição da não discriminação por "sexo" pode ser trazida a discussão quando tratamos das diferenças e discriminações entre homens e mulheres, mulheres e mulheres, homens e homens, como relações de gênero, identidades, expressões e orientações sexuais entre pessoas cis ou transgêneras, pleiteada como uma da forma de proteção aos direitos humanos.

Roger Raupp Rios nos ensina que o princípio da não discriminação deve ser usado quando se refere aos direitos da população LGBTTTQI, por exemplo. Afirma que o artigo $3^{\circ}$, inciso IV, da Constituição de 1988, apesar de não contemplar expressamente a orientação sexual como um dos critérios de discrimi- nação, trata de uma "enumeração exemplificativa", pois "possibilita a inclusão de novos critérios proibidos de discriminação".

Da mesma maneira que o princípio da igualdade leva a pensar no princípio da não discriminação, não há que se falar em efetiva igualdade quando não há respeito ao princípio da liberdade. Além de ser destacada a liberdade individual a partir da escolha de homossexuais pela vivência em conjugalidade, deve ser respeitada a privacidade e a liberdade sexual de cada indivíduo. Elisabeth Roudinesco (2003, p. 9) entende que o "acesso tão esperado a uma justa igualdade dos direitos em matéria de práticas sexuais - para mulheres, para as crianças, para os homossexuais". Assim podemos falar na liberdade e no respeito que todas as pessoas devem ter em relação a intimidade e a vida afetiva de cada pessoa.

0 respeito, então, ao princípio da igualdade permitiria a possibilidade do reconhecimento e do respeito das variadas práticas sexuais. Assim,

Os direitos de liberdade e de privacidade têm desdobramentos evidentes nos direitos sexuais, englobando não só o exercício das preferências sexuais, os estilos de vida e as identidades que se associam à vivência da sexualidade (RIOS, 2011, p. 91).

\section{UNIÃO ESTÁVEL}

A Constituição Federal reconheceu como entidade familiar a conjugalidade formada por duas pessoas, de sexos diferentes, em seu artigo. Posteriormente, por meio da decisão do Supremo Tribunal Federal de 2011, já referenciado, foi reconhecida como união estável a conjugalidade de pessoas do mesmo sexo.

Assim, mesmo que não atravessados pela normalização estatal, seja por meio de uma declaração de união estável ou por um contrato civil de casamento, os casais unidos em uma relação denominada de união estável, reconhecida como a união pública, duradoura e como ânimo de constituir fa- 
mília2, estes casais se sentem e se declaram como "casados" e como "casadas". Em minha pesquisa doutoral (NICHNIG, 2013) percebi, que este reconhecimento como família era importante quando se buscava a concessão de direitos.

A historiadora Maria Odila Leite da Silva Dias (1994) mostra como os arranjos familiares brasileiros não necessitam do prévio contrato de casamento civil para que sejam reconhecidos como família, sendo estes marcados por “improvisações”. Estas são consideradas também como uma nova modalidade de arranjo familiar, como propõe Claudia Fonseca (2008). O que observamos é que há, neste contexto, um reconhecimento social de relações conjugais informais, que permitiu, por exemplo, que o texto constitucional determinasse que a lei deva "facilitar a conversão da união estável em casamento"3. Ou seja, o contexto brasileiro é marcado pela não formalização das relações conjugais, sendo que o casamento civil foi uma formalização imposta pelo estado, mas que muitos sujeitos resistem (e resistiram) a esta imposição, seja por questões econômicas ou por não entenderem como necessária a formalização contratual.

Assim, nestes contextos em que se fazia necessário a prova de uma relação conjugal estável para a demanda por direitos, a única via possível para o reconhecimento do Judiciário era por meio do enquadramento destes casais no conceito de família. É importante ressaltar que também é possível fazer esse registro da união estável durante a vigência da relação conjugal, ou posteriormente por meio de ação judicial de reconhecimento da união estável.

A ministra Carmem Lúcia4, trazendo o debate que foi realizado durante a decisão do processo que reconheceu a união estável para casais do mesmo sexo, fez referência às discussões levantadas durante a Assembleia Constituinte, que ao reconhecer a união estável "entre um homem e uma mulher", não se buscava "a superação de anterior estado de diferenciação inferiorizante de cada uma de nós”. Segundo ela, superar as desiqualdades de gênero, não era o objetivo 2 Artigo $226 \S 3$ da Constituição Federal (BRASIL, 2018).

3 Artigo $226 \S 3$ da Constituição Federal (BRASIL, 2018).

4 Brasil, STF, ADI 4277, Voto Da Ministra Carmem Lúcia, 2011. da inclusão da expressão "entre um homem e uma mulher”, no artigo 226 da Constituição. A ministra Carmem Lúcia conclui ainda que "Nem é de se afirmar que há mera repetição do que posto no inc. I do artigo $5^{\circ}$ e noß30 do art. 226.

Cuida-se de temas que se equilibram, mas não se confundem"5, ou seja, o princípio da igualdade entre homens e mulheres, introduzido pela Constituição Federal no inciso primeiro do artigo 5, não está incluído também no artigo 226 pois, quando se tratou de reconhecer a união estável "entre um homem e uma mulher”, a expressão ali não pretendia resolver desigualdades entre os sexos, mas sim as desigualdades existentes entre as formas familiares. A família formada pela união estável estava à margem do Estado, sendo somente reconhecida aquela formada por meio do casamento civil, vínculo formal reconhecido pela comunidade, instituição legítima em contraposição às ditas uniões informais.

Rios (2011, p. 90) que disciplina sobre o alargamento da união estável para abarcar o direito aos casais do mesmo sexo, afirma que "não reconhecer o valor de uniões homossexuais, de importância ímpar para a existência e realização pessoal, com tão grave comprometimento do modo de viver e de existir do ser humano, é violação frontal à dignidade”.

Por outro lado, quando as relações afetivo-conjugais entre pessoas do mesmo sexo era tido como uma "sociedade de fato", este retirava o caráter familiar da convivência. Inicialmente esta foi a forma com que o judiciário reconheceu as conjugalidades do mesmo sexo no Brasil, sendo somente posteriormente o reconhecimento adas mesmas como entidade familiar, possibilitou um alargamento da proteção legal. Ao permitir o reconhecimento da conjugalidade entre pessoas do mesmo sexo por meio das lentes do direito de família, houve a possibilidade de outros desdobramentos, como o direito a sucessão, aos benefícios previdenciários, entre outros. É importante ressaltar que a categoria da sociedade de fato reflete a realização de um empreendimento conjunto, prin-

5 Brasil, STF, ADI 4277, Voto Da Ministra Carmem Lúcia, 2011, p. $1257 / 1258$, p. 5/6 
cipalmente na questão patrimonial, mas não considera toda a carga afetiva e emocional que envolve um relacionamento afetivo e conjugal.

No tocante à conjugalidade entre pessoas do mesmo sexo, mesmo que grande parte da população reconheça e defenda os direitos dessas pessoas ou, pelo menos, não se oponha a eles, as mudanças sociais não foram acompanhadas por mudanças legislativas.

Ainda que a Constituição Federal determine a proibição de discriminação por gênero e a igualdade entre homens e mulheres, mesmo que as leis impusessem mudanças culturais e sociais, em relação às normas de gênero, as modificações ainda não se realizaram por completo, sendo que são visíveis inúmeras desigualdades em relação às mulheres, em inúmeros setores, como em relação ao acesso ao trabalho, à educação, à igualdade salarial, aos postos de poder e decisão, para citar algumas questões relativas ao trabalho e em questões de âmbito privado, como a dupla ou tripla jornada de trabalho, desigualdades nas relações conjugais, principalmente quando estas desigualdades desencadeiam violências contra as mulheres, que trataremos a seguir.

\section{VIOLÊNCIAS CONTRA AS MULHERES: LEI MARIA DA PENHA}

A Lei Maria da Penha comemora esse ano 22 anos. Talvez, não podemos falar em comemoração já que na maioria das cidades ainda não há os equipamentos necessários para falar na efetiva implementação da lei. Não existem delegacias especializadas suficientes para o atendimento da população, bem como casas abrigo e centros de referência especializados para as mulheres vítimas de violências, espaços privilegiados para que a lei seja plenamente efetivada.

É importante ressaltar que a lei trata principalmente de três medidas, que são: prevenção, proteção e sanção (punição). Irei abordar algumas questões em relação a cada uma delas já que o tema é bastante abrangente e é fruto de inúmeras pesquisas de espe- cialistas na temática (MACHADO, 2013; BRAGAGNOLO, 2012; BANDEIRA, 2014).

Considero um dos mais importantes avanços o conceito que a lei traz de violência de gênero, o que faz com que as pessoas compreendam que existem desigualdades estruturais entre homens e mulheres, que colocam as mulheres em situação de inferioridade social, mesmo que formalmente exista a igualdade jurídica entre ambos. Diante das desigualdades, homens usam diferentes formas de violências contra as mulheres, sendo estas muitas vezes naturalizadas e socialmente legitimadas, ou seja, não consideradas como violências.

Lourdes Maria Bandeira (2014, p. 450) nos alerta que a violência de gênero difere das demais pois é "motivada pelas expressões de desigualdades baseadas na condição de sexo, a qual começa no universo familiar, onde as relações de gênero se constituem no protótipo de relações hierárquicas”. Esta autora alerta-nos ainda para "quem subjuga e quem é subjugado pode receber marcas de raça, idade, classe, dentre outras, modificando sua posição em relação àquela do núcleo familiar". (BANDEIRA, 2014, p. 450). Assim, muitos marcadores sociais da diferença estão presentes nas muitas formas de violências contra as mulheres.

Com o objetivo de controlar a autonomia e a sexualidade das mulheres, quando a suposta honra masculina a ser preservada, as violências aparecem de forma naturalizada, como uma de suas causas, alavancadas por sentimentos como os ciúmes, a não concordância com o fim dos relacionamentos, entre outros. Se falarmos no acesso à Justiça é possível dizer que este não é exercido de forma igualitária paras mulheres, negras, lésbicas, indígenas, pobres e deficientes no Brasil. Muitas destas mulheres tem seus relatos de violências invisibilizados e não ouvidos por familiares e agentes públicos.

Em relação à prevenção é possível falar em avanços e retrocessos. Apesar de que ainda há muito que ser feito, é considerada uma das leis mais conhecidas pela população brasileira. A maioria da população tem conhecimento que cometer violências contra as mulheres pode acarretar a punição pela Lei Maria da 
Penha. Muitos avanços se deram com a realização cursos de formação para professores/as da rede pública de ensino, como o curso gênero e diversidade na escola e inúmeros cursos voltados para a formação para policiais, operadores jurídicos, entre outros que atuam diretamente com a legislação específica. A maioria destes foram interrompidos ou não realizados após o golpe que sofremos em 2016 que desarticulou a Secretaria de Política para Mulheres do Governo Federal, que financiava a formação em relação a temática das mulheres e dos estudos de gênero no Brasil.

Quanto à proteção, podemos dizer que um dos grandes avanços da legislação, a concessão de medidas protetivas a favor das mulheres vítimas de violências, como por exemplo a obrigação do afastamento do agressor em relação à vítima e seus filhos/as, recentemente teve mais uma grande vitória, que é pena de prisão para o descumprimento das medidas concedidas no âmbito da Lei Maria da Penha.

Outra questão que precisa ser debatida nesses trinta anos da Constituição é que se por um lado foi reconhecido naquele momento a necessidade de uma lei para "criar mecanismos para coibir a violência doméstica e familiar contra a mulher", ou seja, que a justiça deveria intervir nas violências e essas deveriam ser punidas e reprimidas por uma aparato policial e judicial, atualmente mecanismos como a "constelação familiar" considerada uma "técnica terapêutica", está sendo largamente utilizada pelo judiciário, em diferentes tribunais de justiça pelo país, para facilitar acordos e "propagar cultura de paz".

Ocorre que em casos e experiências familiares e conjugais atravessadas por violências domésticas não há que se falar em reparação, mas apenas em culpabilização e punição dos agressores. Utilizar destas técnicas pode se transformar em mais uma forma de culpabilização da vítima pela violência sofrida e naturalização das violências, sob o manto da "cultura da paz". É óbvio que se quer uma vida sem violências, mas isso não pode se dar às custas da invisibilização das opressões e desrespeitos, de modo a colocar panos quentes em situações de violação de direitos das mulheres.

\section{CONCLUSÕES}

A existências de dispositivos legais, como os dispostos na Constituição Federal significam avanços significativos. Mas posso concluir que a existência de um dispositivo constitucional ou de uma lei, atua de forma a legitimar certos comportamentos ou a declará-los inadequados, mesmo que não cumprida ou deficiente. No caso da igualdade de gênero, apesar da existência de uma legislação constitucional, que determinava formalmente a igualdade, ainda não representa uma mudança significativa de comportamentos sociais e, pode se dizer que não há uma efetiva igualdade nas relações sociais entre homens e mulheres. Infelizmente vivemos em uma sociedade que legitima a morte de mulheres por seus companheiros e familiares, se não fosse assim não estariam diante de um quadro social que mata mulheres todos os dias no Brasil, vítimas de violências de gênero.

A existência de dispositivos constitucionais, como os que impõem a igualdade formal entre homens e mulheres, são necessários e impõem a criação de uma legislação específica, como é o caso da Lei Maria da Penha. Entretanto, mesmo com a existência de leis, há a necessidade de atuação dos movimentos sociais, principalmente dos movimentos feministas, como meio de pressão para o cumprimento da legislação, ou seja, "para que a lei se transformasse em instrumento de mudança social, se faz necessário que estas transformações legislativas estivessem acompanhadas de um forte e continuado apoio dos movimentos sociais" (TABAK; VERUCCI, 1994, p. 44).

Em relação aos casais do mesmo sexo, mesmo que o Conselho Nacional de Justiça (CNJ) determine que os cartórios devam realizar os casamentos civis, como ainda não há uma alteração legal6, os casais têm seus casamentos anulados por promotores de justiça que desrespeitam o entendimento do Supremo Tribunal Federal (STF) e do CNJ7.

6 Mesmo que haja projeto em tramitação no Senado Federal para alterar o dispositivo do casamento para incluir que o casamento pode ser realizado entre duas pessoas, e não mais entre o homem e a mulher, este dispositivo ainda não foi aprovado. Brasil, Projeto de Lei do Senado $n^{\circ}$ 612, de 2011 Casamento homoafetivo (SENADO FEDERAL, 2011).

$7 \mathrm{Em} \mathrm{2018,} \mathrm{casais} \mathrm{de} \mathrm{mesmo} \mathrm{sexo} \mathrm{de} \mathrm{Santa} \mathrm{Catarina} \mathrm{foram} \mathrm{intimados}$ sobre anulação de seus casamentos pelo promotor de Justiça Henrique 
Já em relação a Lei Maria da Penha, mesmo que seja uma das leis mais conhecidas no Brasil, ou seja, a população de um modo geral reconhece a existência da lei, pode-se dizer que há uma subnotificação das violências no ambiente familiar e doméstico, ainda que a ideia de não interferência de terceiros ou do poder público nas relações privadas (em briga de marido e mulher não se mete a colher) ainda é muito presente em nossa sociedade. Por outro lado, 22 anos depois da implementação da legislação ainda não temos delegacias de proteção à mulher, casos abrigos, centros de referência, treinamento especializados para os operadores do direito de forma suficiente para pensarmos na efetiva implementação da lei.

Ainda que possamos falar em avanços, em relação as duas temáticas aqui abordadas, o reconhecimento pelo Supremo Tribunal Federal que uma relação estável formada por um casal do mesmo sexo e o reconhecimento de que é preciso uma legislação protetiva para as mulheres, como a lei Maria da Penha e a lei do Feminicídio (implementada em 2015, pune com mais gravidade as pessoas que matam mulheres pelo simples fato de serem mulheres, incluindo ainda o feminicídio no rol dos crimes hediondos), também há muito desrespeito em relação as duas questões.

É importante ressaltar que um direito, mesmo que formalmente reconhecido, se faz necessária a vigilância constante dos movimentos sociais na sua aplicação para que o direito conquistado se traduza em políticas públicas para o efetivo gozo dos mesmos pela população. A Lei Maria da Penha é um grande exemplo, pois se comemorar a existência de uma lei com o reconhecimento da existência das violências de gênero no ambiente doméstico e familiar e a criação de medidas para coibí-las é importante, mais importante é vigiar, acompanhar, exigir que todos os mecanismos previstos na legislação efetivamente sejam criados e implementados.

Assim, se a Constituição Federal nos permitiu a construção de importantes alicerces é na prática diária e no ativismo dos movimentos sociais em prol da manutenção e criação de novas políticas públicas

Limongi (DOLCE, 2018). referentes as duas questões aqui debatidas se faz imprescindível. Desta forma, ainda há muito o que ser feito mesmo com a existência de uma legislação em vigor. Precisamos de olhares sensíveis para estas questões, sendo que a aplicação de um feminismo jurídico (SILVA; WRIGHT, 2016; SILVA, 2018) na prática policial e judicial, pode ser um caminho para minimizar as desigualdades reais que vitimam mulheres e pessoas LGBTTTQI no Brasil.

\section{REFERÊNCIAS}

BANDEIRA, Lourdes. Violência de gênero: a construção de um campo teórico de investigação. Sociedade e Estado, v. 29, n. 2, Brasília, p. 440-470, maio/ago. 2014.

BRAGAGNOLO, Regina Ingrid. Experiências e lições em uma vara criminal e juizado de violência doméstica e familiar contra mulher em Santa Catarina. 2012. Tese (Doutorado) - Programa de Pós-Graduação em Psicologia, Centro de Filosofia e Ciências Humanas, Universidade Federal de Santa Catarina, 2012.

BRASIL. Presidência Civil, Casa Civil, Subchefia para Assuntos Jurídicos. Lei $\mathbf{n}^{\mathbf{0}} \mathbf{1 3 . 7 0 9}$, de 14 de agosto de 2018. Dispõe sobre a proteção de dados pessoais e altera a Lei $n^{0} 12.965$, de 23 de abril de 2014. Disponível em: http://www.planalto.gov.br/ccivil_03/_Ato20152018/2018/Lei/L13709.htm. Acesso em:

CORREA, Marisa. Os crimes da paixão. São Paulo: Brasiliense, 1981.

CORREA, Marisa. Morte em família: Representações Jurídicas de Papeis Sexuais. Rio de Janeiro: GRAAL, 1983. 00315p.

CORREA, Marisa;. MATOS, Marlise. Judicialização, Direitos Humanos e cidadania. In: FERREIRA, Lúcia de Fátima Guerra et a/ (org.). Direitos Humanos na Educação Superior: subsídios para a educação em 
direitos humanos nas Ciências Sociais. João Pessoa: Universitária da UFPB, 2010. p. 239-286.

CORREA, Marisa; MATOS, Marlise. Violência conjugal e acesso à justiça: um olhar crítico sobre a judiciarização das relações sociais. In: Antonio Carlos de Souza Lima (org.). Antropologia \& Direito. Temas antropológicos para estudos jurídicos. Rio de Janeiro; Brasília: Contra Capa/LACED/Associação Brasileira de Antropologia, 2012. p. 300-308.

DIAS, Maria Odila Leite da Silva. Novas subjetividades na pesquisa histórica feminista: uma hermenêutica das diferenças. Estudos Feministas, Florianópolis, v. 2, n. 2, p. 373-382, 1994.

DOLCE, Júlia. Promotor que persegue casamentos LGBTs tentou anular 112 uniões em 5 anos. Brasil de Fato, São Paulo, 21 de junho de 2018. Disponível em: https://www.brasildefato.com.br/2018/06/21/ promotor-tenta-anular-casamentos-homoafetivos-em-florianopolis/. Acesso em: 10 ago. 2018.

FONSECA, Claudia. Homoparentalidade: novas luzes sobre o parentesco. Estudos Feministas, v.16, n.3, p. 769-783, 2008.

GOETZ, Anne Marie. Justicia de género, ciudadanía y derechos. Conceptos fundamentales, debates centrales y nuevas direcciones para la investigación. In: MUKHOPADHYAY, Maitrayee; NAVSHARAN, Singh. Justicia de género, ciudadanía y desarrollo. Colombia: Mayol Ediciones, 2008. p. 13-45.

GONZÁLEZ GARCÍA, Marta I.; PÉREZ SEDEÑO, Eulalia. Ciencia, tecnologia y género. Revista Iberoamericana de Ciencia, Tecnologia, Sociedad y Innovación, n. 2, enero/abril 2002.

HARAWAY, Donna. Saberes localizados: a questão da ciência para o feminismo e o privilégio da perspectiva parcial. Cadernos Pagu, Campinas, v. , p. 7-41, 1995.
HARDING, Sandra. Existe un método feminista? In: BARTRA, Eli (org.). Debates en torno a una metodología feminista. 2. México UAM-X, CSH, 2002. p. 9-34.

JUREMA, Solange Bentes. Ações e estratégias do CNDM para o "empoderamento" das mulheres. Estudos Feministas, Florianópolis, v. 9, n. 1, p. 207-212, 2001.

MACHADO, Isadora Vier. Da dor no corpo à dor na alma: uma leitura do conceito de Violência Psicológica da Lei Maria da Penha. 2013. Tese (Doutorado) - Programa Doutorado Interdisciplinar em Ciências Humanas, Centro de Filosofia e Ciências Humanas, Universidade Federal de Santa Catarina, 2013.

NICHNIG, Claudia Regina. Para ser digno há de ser livre: reconhecimento jurídico da conjugalidade entre pessoas do mesmo sexo no Brasil. 2013. Tese (Doutorado) - Programa Doutorado Interdisciplinar em Ciências Humanas, Centro de Filosofia e Ciências Humanas, Universidade Federal de Santa Catarina, 2013.

NIGRO, Rachel. Decisão do STF sobre a união homoafetiva: uma versão pragmática da linguagem constitucional. Direito, Estado e Sociedade, n. 41, p. 157183, jul./dez. 2012.

PERLINGIERI, Pietro. Perfis do direito civil. Tradução de Maria Cristina De Cicco. 2. ed. Rio de Janeiro: Renovar, 2002.

REYNADO, Renata Guimarães. Marcha Mundial de Mulheres: um enfoque pós/decolonial sobre intersecções e solidariedades no feminismo transnacional. 2016. Tese (Doutorado) - Programa do Doutorado Interdisciplinar em Ciências Humanas, Centro de Filosofia e Ciências Humanas, Universidade Federal de Santa Catarina, Florianópolis, 2016.

RIFIOTIS, Theophilus. Judiciarização das relações sociais e estratégias de reconhecimento: repensando a 
violência conjugal e a violência intrafamiliar. Katál, Florianópolis, v. 11, n. 2, p. 225-236, 2008.

RIOS, Roger Raupp; GOLIN, Célio; LEIVA, Paulo Gilberto Cogo. Homossexualidade e direitos sexuais: reflexões a partir da decisão do STF. Porto Alegre: Sulina, 2011.

ROUDINESCO, Elisabeth. A família em desordem. Trad. André Telles. Rio de Janeiro: Jorge Zahar, 2003.

SEnAdo fEDERAL. Atividade Legislativa. Projeto de

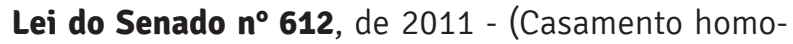
afetivo). Autoria: Senadora Marta Suplicy (PT/SP). Brasília, 2011. Disponível em: https://www25.sena- do.leg.br/web/atividade/materias/-/materia/102589. Acesso em: 10 ago. 2018.

SILVA, Salete Maria da. Feminismo jurídico: uma introdução. Cadernos de Gênero e Diversidade, Salvador, v. 4, n. 1, p. 83-102, 2018.

SILVA, Salete Maria da; WRIGHT, Sonia Jay. Uma reflexão feminista sobre o conceito de Justiça de Gênero. Teorias da Justiça, da Decisão e da Argumentação Jurídica, v. 2, n. 1, p. 216, 2016.

TABAK, Fanny; VERUCCI, Florisa. A difícil igualdade: os direitos da mulher como direitos humanos. Rio de Janeiro: Relume-Dumará, 1994.
Data da submissão: 10 de Agosto de 2018

Avaliado em: 23 de Agosto de 2018

Avaliado em: 05 de Setembro de 2018

Aceito em: 06 de Setembro de 2018
1 Professora visitante do Programa de Pós-Graduação em História, da Universidade Federal da Grande Dourados - UFGD; Pós-doutora em História, pela Universidade Federal de Santa Catarina - UFSC e em Antropologia Social pela École des hautes études en sciences sociales - EHSS, em Toulouse/França. Este texto foi inspirado na tese de doutorado intitulada "Para ser digno há de ser livre: reconhecimento jurídico da conjugalidade entre pessoas do mesmo sexo no Brasil”, defendida em 2013, no Programa Doutorado Interdisciplinar em Ciência Humanas da UFSC, na área de Estudos de Gênero. E-mail: claudianichnig@gmail.com. 
